\title{
Festejar e repensar a Independência: um balanço
}

\section{Celebrating Independence and rethink: a balance}

\author{
Hendrik Kraay* \\ Jurandir Malerba**
}

O gosto pelos números redondos parece ser algo inato ao homem moderno. Atribuímos muito mais significado ao centenário do que ao nonagésimo nono aniversário ou ao centésimo primeiro, embora tudo isso seja muito arbitrário. $\mathrm{O}$ ano de 2010 marca o bicentenário da Independência da América espanhola, lembrado por meio de inúmeras conferências, dossiês temáticos em revistas acadêmicas como esta, além de diversas solenidades oficiais e festas populares. Em Calgary, no Canadá, o consulado mexicano e a comunidade de origem mexicana promoveram uma semana de festas em torno do dia 16 de setembro para lembrar o Grito de Dolores, de Miguel Hidalgo, que lançou o movimento pela Independência mexicana em 1810. Até a Calgary Philharmonic Orchestra (Orquestra Filarmônica de Calgary) apresentará um concerto de música de compositores mexicanos, algo bem raro nas salas de concerto internacionais. ${ }^{1}$

Quando se comemorou o primeiro cinquentenário da Independência, porém, parece que não houve tal entusiasmo. No Rio de Janeiro, no dia 7 de setembro de 1872, inaugurou-se a estátua de José Bonifácio de Andrada e Silva no Largo de São Francisco, mas a retórica da solenidade (e do resto das comemorações oficiais e populares daquele dia) fez pouco caso de o Brasil fazer cinquenta anos. ${ }^{2} \mathrm{Na}$ historiografia, ainda escassa

\footnotetext{
* Professor do Departamento de História, Universidade de Calgary.

** Professor do Departamento de História, PPGH, PUCRS.

1 Ver o portal oficial das comemorações em Calgary, http://www.mexicanbicentennial.com/ (acesso em 27 de julho de 2010).

2 Sobre a inauguração da estátua, ver Paulo Knauss e Hendrik Kraay, "A inauguração da estátua de José Bonifácio na visão de um correspondente estrangeiro, em 7 de setembro de 1872”, Revista do Instituto Histórico e Geográfico Brasileiro, no prelo.
} 
sobre as comemorações da Independência hispano-americana, também não há indícios de comemorações especiais nos cinquentenários. ${ }^{3}$

O centenário da Independência despertou muito mais interesse. No México, o regime de Porfírio Díaz fez uma grande comemoração oficial em 1910 (mas foi derrubado pela revolução mexicana no ano seguinte). ${ }^{4}$ Depois da Primeira Guerra Mundial, houve uma nova rodada de centenários. O Brasil realizou a exposição internacional de 1922; os países da América central, que dataram a sua independência quando da separação das efêmeras Províncias Unidas da América Central do ainda mais efêmero império Mexicano (o qual ocorreu em 15 de setembro de 1821), também festejaram ruidosamente a sua emancipação política. ${ }^{5}$ Nessas comemorações, destacou-se o progresso, a modernidade, e certa visão de unidade hispano-americana face à ameaça do poder e da influência crescentes dos Estados Unidos.

No século XX, tornou-se moda comemorar centenários. Só no Brasil, pode-se mencionar (entre outros) o quarto centenário do Descobrimento (1900), o centenário da Independência (1922), centenários da fundação de grandes cidades (Salvador, 400 anos em 1949 e 450 anos em 1999; Rio de Janeiro, 400 anos em 1965; e São Paulo, 400 anos em 1954), o sesquicentenário da Independência (1972), o quinto centenário do Descobrimento (2000) e o recente bicentenário da chegada de D. João (2008). ${ }^{6} \mathrm{O}$ quinto centenário do Descobrimento do Brasil foi tão

David Díaz Arias, La fiesta de la independencia en Costa Rica, 1821-1921. San José: Editorial Universidad de Costa Rica, 2007; William H. Beezley e David E. Lorey (orgs.), ¡Viva Mexico! ;Viva la Independencia! Celebrations of September 16. Wilmington: Scholarly Resources, 2001; José María Salvador, Efimeras efemérides: Fiestas civicas y arte efimero en la Venezuela de los siglos XVIII-XIX. Caracas: Universidad Católica Andrés Bello, 2001.

4 Annick Lempérière e Lucrecia Orensanz, "Los dos centenarios de la Independencia mexicana (1910-1921): De la historia patria a la antropologia cultural", Historia Mexicana 45:2 (outubro de 1995): 317-52; Mauricio Tenorio Trillo, "1910 Mexico City: Space and Nation in the City of the Centenario", Journal of Latin American Studies 28:1 (fevereiro de 1996): 75-104; Michael J. Gonzales, "Imagining Mexico in 1910: Visions of the Patria in the Centennial Celebration in Mexico City", Journal of Latin American Studies 39:3 (agosto de 2007): 495-533.

5 Marly Silva da Motta, A nação faz 100 anos: A questão nacional no centenário da Independência. Rio de Janeiro: Editora da Fundação Getúlio Vargas, 1992; Ana Patricia Fumero-Vargas, "National Identities in Central America in a Comparative Perspective: The Modern Public Sphere and the Celebration of Centennial of Central American Independence, September 15, 1921". Tese de doutorado, University of Kansas, 2005.

6 Sobre alguns desses centenários, há estudos: Lucia Lippi Oliveira, "Imaginário histórico e poder cultural: As comemorações do descobrimento", Estudos Históricos 14 (junho de 2000): 183-202; Maria Helena Ochi Flexor, "A rede urbana e os festejos centenários da Bahia em 1949”, Revista da SBPH 21 (2001): 109-29; Dulce Maria Pamplona Guimarães, 
fracassado quanto as propaladas comemorações do quinto centenário do Descobrimento das Américas em 1992. Os protestos dos movimentos indígenas e a nova visão crítica do legado de Colombo efetivamente negaram o tom ufanista dos festejos oficiais. ${ }^{7}$

Para os historiadores, essas comemorações são fontes para pensar a memória coletiva, a invenção das tradições, a construção das nações e a contestação política manifestada nas polêmicas suscitadas por elas. Foram e são incentivos à produção de novos estudos históricos, sejam ufanistas, sejam polêmicos e críticos. Às vezes, abriram espaço para historiadores intervirem em debates públicos.

O que está sendo comemorado este ano? Alguns jornalistas, literais demais, têm criticado a escolha de 2010 como o ano do bicentenário, pois os movimentos de 1810 ainda se declararam leais a Fernando VII, e a Independência efetiva só foi realizada anos depois. ${ }^{8}$ Não entenderam que se trata de comemorar o começo do processo que resultou nas independências. Aliás, este já é um debate muito velho. Como assina William H. Beezeley, no México das décadas de 1820 a 1840, os conservadores preferiram comemorar a Independência no dia 27 de setembro, data da entrada de Augustín Iturbide (o futuro e malogrado imperador Augustín I) na Cidade de México em 1821. Os liberais festejaram Hidalgo e o Grito de Dolores onze dias antes. Aqueles tenderam a ver a Independência como algo completo, enquanto estes comemoraram o início de um processo que, para eles, ainda faltava completar com reformas liberais. ${ }^{9}$ Da mesma forma, pode-se dizer que as nações são obras ainda incompletas e as comemorações de 2010

\footnotetext{
"Festa de fundação: Memória da colonização nas comemorações do IV Centenario da cidade de São Paulo", História 13 (1994): 131-39; Iara Lis Schiavinatto, “A praça pública e a liturgia política", Cadernos CEDES 22:58 (dezembro de 2002): 92-96; Kelly Cristiane da Silva, "A nação cordial: Uma análise dos rituais e das ideologias oficiais de "Comemoração dos 500 Anos do Brasil"”, Revista Brasileira de Ciências Sociais 18:51 (fevereiro de 2003): 141-59; Jurandir Malerba, "Brasil joanino no horizonte da história", Teoria e Debate 75 (2008): 40-44.

7 Stephen J. Summerhill e John Alexander Williams, Sinking Columbus: Contested History, Cultural Politics, and Mythmaking during the Quincentenary (Gainesville: University Press of Florida, 2000); Jeremy Smith, "Outside and Against the Quincentenary: Modern Indigenous Representations at the Time of the Columbian Celebrations", Atlantic Studies 6:1 (abril de 2009): 63-80.

8 Ver, por exemplo, Armen Kouyoumdjian, “2010 Is By No Means Chile's Bicentennial” (http://www.newropeans-magazine.org) (acesso em 27 de julho de 2010); e German Patiño, "Dia de la Independencia", El País (Bogotá), 18 de julho de 2010 (www.elpais.com.co) (acesso em 27 de julho de 2010).

9 William H. Beezeley, Mexican National Identity: Memory, Innuendo, and Popular Culture. Tucson: University of Arizona Press, 2008, 56-57.
} 
são uma oportunidade para retomar debates sobre cidadania, direitos e participação política, temas amplamente discutidos na época da Independência, e ainda hoje questões correntes.

Os portais das comemorações oficiais mantidas pelos governos hispano-americanos mostram uma enorme variedade de atividades comemorativas, desde os tradicionais desfiles militares e as inaugurações de obras públicas a concertos de música popular, exposições de arte, conferências acadêmicas e publicações de livros comemorativos. Há espaços para a participação de crianças e grupos facebook para os adeptos das comemorações. ${ }^{10} \mathrm{O}$ tom dominante é ufanista e se destaca a unidade da nação, seja qual for, e sua capacidade de incorporar todos.

Não faltam críticos. A crise atual no México levou o historiador mexicano Mauricio Tenorio Trillo, em entrevista de 2009, a comentar que

Nuestro bicentenario va a ser una especie de pan mal cocido, porque no hay una clara idea del presente y del futuro, no porque la historia nos haya fallado o no haya suficientes debates historiográficos, ni pleitos entre los especialistas; pero eso no te dice cómo celebrar, sino la idea del presente y del futuro. ${ }^{11}$

A prestigiada revista Time chegou a lembrar que a Revolução Mexicana começou em 1910, cem anos depois da insurgência promovida por Hidalgo; pergunta-se se a história se repetirá. ${ }^{12}$ Não obstante sua visão simplista da História, o artigo apontou os sérios problemas econômicos, sociais e políticos enfrentados atualmente pelo México que levaram alguns a temer uma nova revolução.

Na Bolívia, a comemoração dos duzentos anos da revolta de Charcas (atual Sucre), de 25 de maio de 1809, foi marcada por intensas discussões sobre a memória histórica. A oposição ao presidente Evo Morales rejeitou as solenidades oficiais e condenou o que via como a exclusão do passado colonial das comemorações e a ênfase excessiva na cultura aymara. ${ }^{13}$ Grupos indígenas protestaram contra as comemorações

${ }^{10}$ Dado a natureza efémera da internet, seria ocioso apresentar os URLs aqui. É de esperar que alguém arquive esses portais para futuros historiadores.

11 "Centenários, ocasión para 'festejar presente y futuro"”, Milenio, 5 de agosto de 2009, http://impreso.milenio.com (acesso em 27 de julho de 2010).

12 Tim Padgett with Dolly Mascareñas, "Why Mexico is Anxious about Its Bicentennial," Time, 31 de dezembro de 2009, www.time.com (acesso em 28 de julho de 2010).

${ }^{13}$ Mabel Azcui, "Bolivia excluye el pasado criollo en el bicentenario de la independencia," El País (Madrid), 15 de julho de 2009, www.elpais.com (acesso em 28 de julho de 2010). 
do bicentenário na Colômbia. ${ }^{14}$ Para Hugo Chávez, discursando no dia 19 de abril, o bicentenário da instalação da primeira junta de Caracas, "Llegó la hora de nuestra verdadera independencia, 200 años después."15 O uso do símbolo de Simón Bolívar pelo regime chavista também remonta diretamente à história da Independência venezuelana. Assim, uma leitura rápida das comemorações do bicentenário permite uma radiografia da conjuntura latino-americana atual.

É nesse contexto que reunimos esse dossiê de artigos sobre aspectos da história da Independência. Nenhum dos autores está inspirado diretamente pelo bicentenário e todos os textos são trabalhos históricos originais que analisam diversos aspectos das complicadíssimas lutas pela Independência. Eles apontam alguns temas que vale a pena aprofundar: o contexto atlântico, os militares, a participação popular e o impacto da Independência fora das grandes capitais.

Embora as comemorações dos bicentenários sejam eventos nacionais e nacionalistas, não existiam nações em 1810 ou em 1822; o contexto atlântico marcou profundamente a conjuntura das independências e os temores e as aspirações dos homens e das mulheres que vivenciaram as grandes mudanças. Como apontam Stefan Rinke e Frederik Schulze, Francisco de Mirando sonhava em libertar não apenas a Venezuela, mas todo o continente "columbiano-americano". Face às novas conjunturas econômicas e políticas no mundo atlântico, os impérios tentaram implantar reformas ilustradas no século XVIII, as quais às vezes acabaram por alienar as elites coloniais. As revoluções norte-americanas, francesas e haitianas rejeitaram as grandes verdades do Antigo Regime (e do seu ramo escravista nas Américas), e moldaram os processos que levaram às independências. Os rebeldes pernambucanos de 1817 buscaram apoio nos Estados Unidos; se não chegaram a mandar Félix José Tavares Lira a Buenos Aires ou Assunção, como mostram Luiz Geraldo Silva e João Paulo G. Pimenta, não há dúvida de que viam o governo portenho como um possível aliado e que foram influenciados pelos ideais de republicanismo e federalismo. E essas conexões tinham uma forte base econômica nas redes comerciais das quais Tavares Lira fazia parte. ${ }^{16}$

\footnotetext{
14 "Indígenas cuestionam las celebraciones del bicentenario", 19 de julho de 2010, www. periodismopublico.com (acesso em 28 de julho de 2010).

15 "Chávez celebra Bicentenário de independencia con aliados", El Nuevo Diario (Manágua), 19 de abril de 2010, www.elnuevodiario.com.ni (acesso em 28 de julho de 2010).

${ }^{16}$ Para uma tentativa recente de ligar estruturas econômicas e mudanças políticas no sulatlântico ibérico, ver Jeremy Adelman, Sovereignty and Revolution in the Iberian Atlantic (Princeton: Princeton University Press, 2006).
} 
Para o Brasil, é bom lembrar, o mundo atlântico era também africano. De certa forma, a biografia de Rufino José Maria pode servir de contraponto à de Miranda. Natural de Oyo (na atual Nigéria), foi escravizado aos 17 anos e levado à Bahia, aonde chegou à época da guerra pela Independência (1822-23). Aprendeu o ofício de cozinheiro e foi levado no final da década ao Rio Grande do Sul pelo filho do seu senhor, um cadete do exército brasileiro que defendia a fronteira com a recém-independente República Oriental. Adquiriu meios para comprar sua liberdade em Porto Alegre. Pouco depois da eclosão da Revolução Farroupilha, voltou ao Rio de Janeiro e empregou-se no comércio africano como cozinheiro de navio. ${ }^{17}$ Quando contou a sua trajetória de vida, Rufino não disse nada sobre o que ele viu e ouviu das lutas pela Independência baiana, uruguaia e rio-grandense (se é que podemos pensar a Farroupilha como um movimento pela Independência). Todavia, milhares e milhares de escravos, homens livres de cor, e membros das classes baixas participaram das lutas e testemunharam as mudanças políticas, sem falar dos povos indígenas. ${ }^{18}$

Chamar atenção aos aspectos populares das lutas pela Independência não significa negar que os novos regimes fossem relativamente conservadores, que o tráfico e a escravidão perdurassem no Brasil independente, que os latifundiários continuassem a dominar a sociedade rural. Mesmo assim, houve mudanças. Gabriel Di Meglio e Marixa Lasso chamam atenção para esse aspecto da história da Independência. Para Di Meglio, a mobilização popular em Buenos Aires na década de 1810 significou que "nada volveria a ser igual." Para Lasso, a resposta à exclusão racial das Cortes espanholas e a necessidade de mobilizar uma parcela significativa da população de cor na Grã Colômbia fundiu o patriotismo e a igualdade racial numa nova ideologia nacionalista. ${ }^{19}$ Houve, sim, uma reação e as acusações de promover uma guerra racial

${ }^{17}$ Sobre Rufino, ver o resumo do interrogatório dele publicado em Carta particular, Recife, 16 de setembro de 1853, Jornal do Commercio (Rio de Janeiro), 25 de setembro de 1853. A história de Rufino foi analisado por João José Reis, Flávio dos Santos Gomes e Marcus J. M. de Carvalho, que não especulam sobre as possíveis experiências políticas dele, "África e Brasil entre margens: Aventuras e desventuras do africano Rufino José Maria, c. 18221853," Estudos Afro-Asiáticos 26:2 (2004): 256-302.

${ }^{18}$ Para uma história dos movimentos da Independência que leva a participação popular a sério, ver John Charles Chasteen, Americanos: Latin America's Struggle for Independence. New York: Oxford University Press, 2008.

19 Para fazer jus às Cortes espanholas, é preciso dizer que decretaram a igualdade legal para a população indígena e não instituíram nenhuma restrição censitária ao voto; sobre a importância dessa democratização, ver Jaime Rodríguez O., The Independence of Spanish America. Cambridge: Cambridge University Press, 1998), 81-82, 92. 
foram uma maneira efetiva de restringir a mobilização pós-independência dos afro-descendentes colombianos. No Brasil, condenar o haitianismo tinha o mesmo fim e, em 1830, Evaristo Ferreira da Veiga lamentou que exaltados e até moderados eram alvos da "costumada lamúria de S. Domingos." ${ }^{20}$ Di Meglio e Lasso sugerem como podemos incluir os Rufinos na história da Independência. ${ }^{21}$

Tanto no México como na América do Sul espanhola, e mesmo em algumas regiões brasileiras, a Independência foi caracterizada por lutas militares. Rufino, aliás, não falou da luta pela Independência na Bahia, mas da "guerra com Madeira," uma referência a Luís Inácio Madeira de Melo, comandante das tropas lusas assediadas em Salvador por patriotas baianos em 1822-23, um indício de como se lembravam esses episódios. É verdade que as batalhas na América espanhola mal passariam de escaramuças, se medidas pelos padrões europeus das guerras napoleônicas, mas as lutas não deixaram de ser cruentas, violentas e até catastróficas para populações em determinadas regiões. Por outro lado, as guerras foram de alta importância para a formação das forças armadas nos novos Estados independentes. Os oficiais realistas novohispanos estudados por Christon Archer formaram o cerne e a cúpula da oficialidade mexicana. Sua atuação política derivou diretamente da sua experiência na luta contra os insurgentes patriotas, durante a qual se imbricaram na política local e estabeleceram as bases econômicas e políticas para suas carreiras no período pós-independência. O pacto entre realistas e patriotas que levou à Independência mexicana foi uma experiência única na América espanhola, e os oficiais espanhóis derrotados na América do Sul tiveram que voltar para uma Espanha absolutista (com seu muito reduzido império), como demonstra Justo Cuño Bonito. Tanto na Espanha como nas ex-colônias, as lutas entre liberais e conservadores continuaram, e não foi fácil para o Brigadeiro Gabriel de Torres y Velasco conseguir um conselho de guerra perante o qual ele pudesse justificar a sua conduta. Na conjuntura política de 1827, quando prevalecia o silêncio sobre as lutas recentes, isso ainda foi possível.

${ }_{20}$ Aurora Fluminense (Rio de Janeiro), 29 de março de 1830.

${ }^{21}$ Para tentativas de pensar a participação popular nas lutas pela Independência brasileira, ver José Celso de Castro Alves, "Plebeian Activism, Popular Constitutionalism: Race, Labor, and Unrealized Democracy in Rio de Janeiro, Brazil, 1780s-1830s" (tese de doutorado, Yale University, 2006); Hendrik Kraay, "Muralhas da Independência e liberdade do Brasil: A participação popular nas lutas políticas (Bahia, 1820-1825)", in: MALERBA, Jurandir (org.). A Independência brasileira: Novas dimensões, Rio de Janeiro: Editora da Fundação Getúlio Vargas, 2006, 303-41. 
Há um ditado em inglês que reza que toda a política é local (All politics is local). Ao sair da capital e estudar os povos rurais na região platina, Raúl O. Fradkin demonstra que eles não estavam ausentes do processo da independência, que participaram das mesmas lutas da população portenha. Houve um processo de descentralização política semelhante ao que ocorreu na Nova Espanha durante os períodos de vigência da Constituição de 1812. Archer também salienta a importância das questões locais ao analisar como os oficiais realistas construíram suas bases políticas. No Brasil, as reformas liberais que criaram a figura do juiz de paz e a Guarda Nacional, com seus oficiais eleitos, todos posteriores à Independência propriamente dita, talvez tivessem um impacto semelhante ao que ocorreu na região platina duas décadas antes, no sentido de conturbar o poder local.

Nas suas notas sobre a primeira tradução portuguesa dos Anais de Tácito, Valdei Lopes de Araujo mostra como o historiador romano serviu de modelo para compreender o mundo político, sujeito a tantas mudanças rápidas nessas décadas. Os Anais podiam ser lidos como um modelo para conciliar a liberdade e a autoridade, esta tão cara a conservadores como José da Silva Lisboa; para Hipólito José da Costa e José Liberato Freire de Carvalho, o historiador romano criticava o despotismo. Assim, Araujo chama atenção a aspectos da cultura política da elite letrada, sua apropriação da Antiguidade; resta por saber se e como foram compreendidas essas alusões pelos leitores dos periódicos (ou os analfabetos que só tinham acesso a esses textos quando eram lidos em voz alta ou discutidos em praça pública).

Desde a virada do século - mais um desses benditos números redondos pelos quais marcamos as nossas vidas! - houve um enorme avanço pela historiografia brasileira, encetado por inúmeros novos estudos sobre a Independência. ${ }^{22}$ A história brasileira lucrará com mais atenção à experiência hispano-americana. "La variante moderada brasileña constituyó parte integral de um processo americano", observam Rinke e Schulze, e este dossiê sugere alguns dos caminhos que podemos seguir para aprofundar a análise dessa época ainda importante para a compreensão da realidade brasileira e latino-americana.

\footnotetext{
${ }^{22}$ Coletâneas importantes incluem István Janscó (org.), Brasil: Formação do Estado e da nação. São Paulo: Hucitec, 2003; idem. Independência: História e historiografia. São Paulo: Hucitec, 2005; Malerba (org.), A Independência brasileira.
} 